\title{
Synthesis of Heterogeneous Copper Catalyst Based on Amino-Functionalized Triazine Rings Supported by Silica-Gel for Oxidation of Alcohols
}

\author{
Majid Kolahdoozan, ${ }^{1,2}$ Roozbeh Javad Kalbasi, ${ }^{1}$ and Mahshid Hossaini ${ }^{1}$ \\ ${ }^{1}$ Department of Chemistry, Shahreza Branch, Islamic Azad University, Shahreza 311-86145, Esfahan, Iran \\ ${ }^{2}$ Young Researcher Club, Shahreza Branch, Islamic Azad University, Shahreza 311-86145, Esfahan, Iran
}

Correspondence should be addressed to Majid Kolahdoozan; kolahdoozan@iaush.ac.ir and Roozbeh Javad Kalbasi; rkalbasi@gmail.com

Received 23 December 2011; Accepted 15 May 2012

Academic Editor: Alexander Kornienko

Copyright (C) 2013 Majid Kolahdoozan et al. This is an open access article distributed under the Creative Commons Attribution License, which permits unrestricted use, distribution, and reproduction in any medium, provided the original work is properly cited.

\begin{abstract}
Amino-functionalized triazine supported on silica-gel was prepared. This new triazine derivate was applied as a coordinating agent for copper (II) and was characterized by different methods. The copper (II) content of the material was determined by atomic absorption. This novel transition metal supported on heterogeneous surface was used as an effective catalyst for oxidation of benzylic alcohols in the presence of $\mathrm{H}_{2} \mathrm{O}_{2}$. This catalyst can be reused without any significant loss of activity.
\end{abstract}

\section{Introduction}

1,3,5-Triazine derivatives have found widespread applications in the pharmaceutical, textile, plastic, and rubber industries and are used as pesticides, dye stuffs, optical bleaches, explosives, and surface active agents [1].

Recently, there has been a growth of interest in the use of cyanuric chloride (2,4,6-trichloro-1,3,5-triazine) in a wide range of functional group transformations. The ease of displacement of chlorine atoms in cyanuric chloride by various nucleophiles, in the presence of an acid acceptor, makes this reagent useful for the preparation of mono-, di, and tri-substituted 1,3,5-triazines [2]. Cyanuric chloride is one of the most widely used linking agents, as it can react with carbon active surface [3, 4], clay [5], quartz surface [6], modified resins $[7,8]$, glass slide [9], and with a variety of substances, including hydroxyl and amino compounds, alkyl and aryl Grignard reagents, and organic hydrazine derivatives [3]. Interestingly, in most of these cases, the use of cyanuric chloride presents advantages compared to other classical methods in terms of cost, yield, and mildness. Thus, in the light of these results, the discovery of new applications for cyanuric chloride in organic synthesis is of interest.
Selective oxidation of alcohol into an aldehyde or ketone is an important transformation in organic synthesis, and various methods are known for this particular conversion. Aldehydes are an important class of compounds used as food additives and as intermediates in organic syntheses such as Aldol condensation, Micheal addition, Cannizaro and Perkins reactions. To achieve selective oxidations, various homogeneous catalysts and combined catalysts have been reported in the literature [10-16]. Homogeneous catalysts have enormous relevance in various organic reactions. However, homogeneous catalysts have some disadvantages in that they can decompose during the course of the reaction and are not easily recovered after the reaction for reuse. This leads to the loss of metal and ligands and incorporation of impurities in the products. Also, these oxidation reactions are often performed in solvents such as chlorinated hydrocarbons, which can have an adverse environmental impact when practiced on an industrial scale. Immobilization of homogeneous catalysts on solid supports often presents advantages due to easy separation from the product mixture by simple filtration, high catalytic activity, stability, and selectivity in comparison to unsupported metal complexes where the industrial demand of recyclability for continuous operation 
TABLE 1: The effect of solvent for oxidation of benzyl alcohol ${ }^{\mathrm{a}}$.

\begin{tabular}{lcc}
\hline Solvent & Time $(\mathrm{min})^{\mathrm{b}}$ & Yield $(\%)$ \\
\hline Acetonitrile & 65 & 55 \\
Solvent free & 45 & 42 \\
Toluene & 85 & 70 \\
Acetone & 240 & 73 \\
$n$-Hexane & 35 & 80
\end{tabular}

All reactions were carried out in the reflux condition in the presence of $0.15 \mathrm{~g}$ catalyst and $3 \mathrm{mmol} \mathrm{H}_{2} \mathrm{O}_{2}$.

${ }^{\mathrm{b}}$ Time of maximum conversion.

can be met. Due to these inherent advantages of heterogeneous catalysts over homogeneous catalysts, a great deal of effort has been devoted to the development of heterogeneous catalysts. In the literature, many heterogeneous catalysts have been proposed for oxidation of alcohols to aldehydes or ketones. For example, benzylic alcohols were oxidized to the corresponding carbonyl compounds in good to high yields by environmentally friendly and green oxidant, $\mathrm{H}_{2} \mathrm{O}_{2}$ catalyzed by montmorillonite $\mathrm{K}-10$ supported cobalt (II) chloride in a rather long reaction time [17]. Selective oxidation of benzyl alcohol to benzaldehyde catalyzed by $\mathrm{Cr}($ salen) complexes immobilized on MCM-41 was performed by $\mathrm{H}_{2} \mathrm{O}_{2}$ but showed low conversion [18]. Also, oxidation of alcohols by $\mathrm{Cu}(\mathrm{II})$ complexes immobilized by different ligands on silicate layers of bentonite was reported in the presence of tert-butylhydroperoxide (TBHP) as an oxidant with good selectivity but low conversion [19].

In order to provide a more environmentally benign "green" process for alcohol oxidations, a variety of methods for using transition metal catalysts with more mild oxidants such as $\mathrm{H}_{2} \mathrm{O}_{2}$ have been investigated [20]. Hydrogen peroxide is an attractive, atom-economic, and environmentally benign oxidant as it is cheap, easily available, nontoxic which produces only water as a by-product [21].

The problems associated with homogeneous catalysts prompted us to investigate and design a novel heterogeneous oxidizing catalyst for conversion of alcohol to aldehyde with improved selectivity and conversion efficiency. The goal of this work is to support copper (II) on a silica-gel surface via a novel modification technique using an aminated triazine ring in order to increase adhesion with deposited metal.

\section{Experimental}

2.1. Materials and Solvents. The reagents and solvents were purchased from Merck, Fulka, and Aldrich Chemical companies and were used as received. Silica-gel (particle size 20-63 $\mu \mathrm{m}, 70-230$ mesh pore size $100 \AA$ ), ethylenediamine (EDA), cyanuric chloride, triethylamine (TEA), and copper acetate were purchased from Merck Chemical Company and used without further purification. In order to dry tetrahydrofuran (THF), it was distilled off over sodium in the presence of benzophenone after its color changed to deep blue.

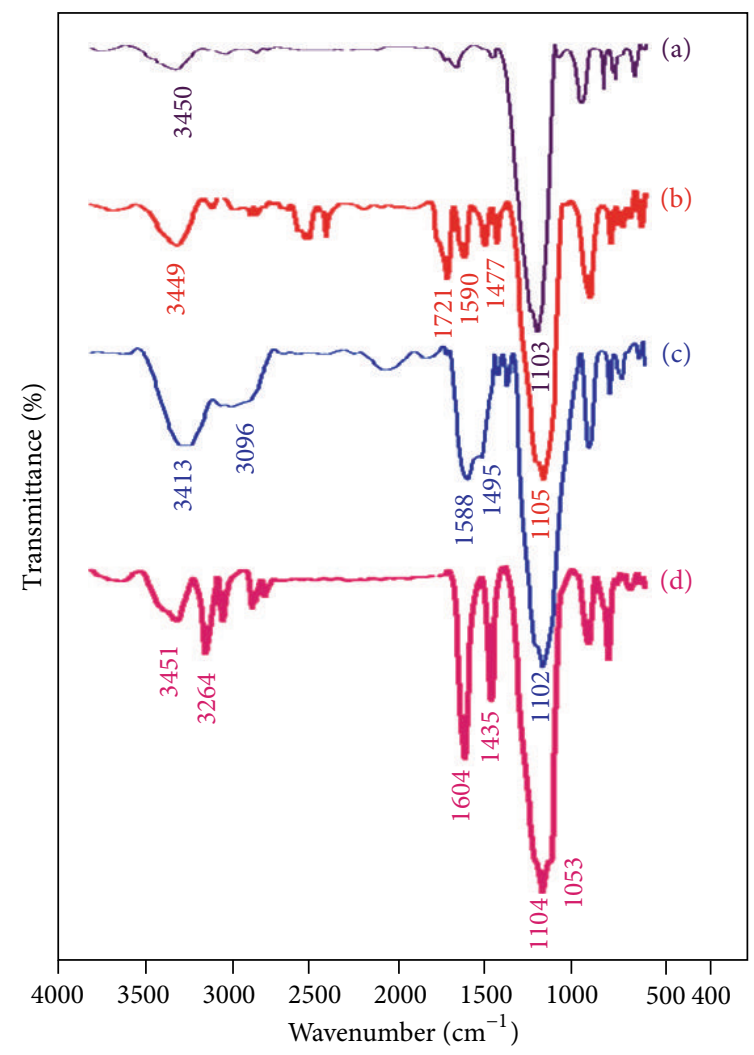

FIgURE 1: FT-IR spectra for (a) silica-gel, (b) CC-silica, (c) AT-silica, and (d) Cu/AT-silica.

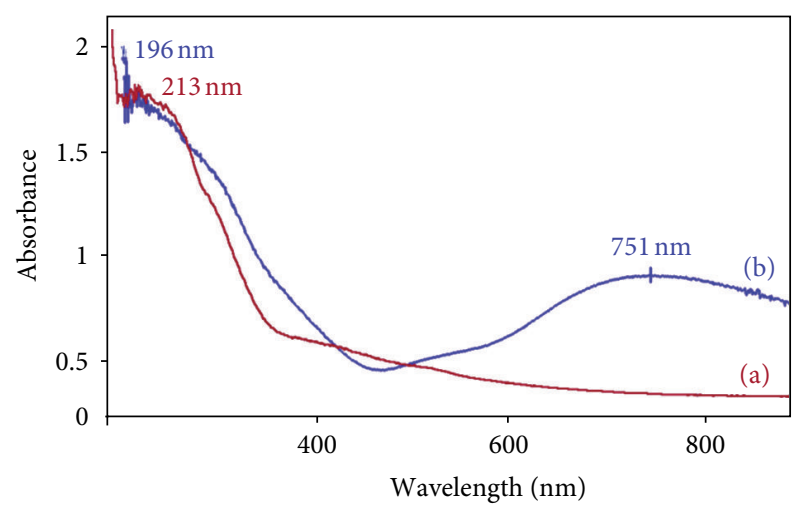

FIgURE 2: DR UV-vis spectra of (a) AT-silica and (b) Cu/AT-silica.

2.2. Preparation of Cyanuric Chloride Supported on Silica-Gel. Silica-gel $(1.2 \mathrm{~g})$ and $10 \mathrm{~mL}$ dry tetrahydrofuran (THF) in a 25 round bottom flask were cooled in an ice bath. TEA $(0.5 \mathrm{~mL})$ was added and stirred for $10 \mathrm{~min}$. Then, cyanuric chloride $(1.2 \mathrm{~g}, 6.5 \mathrm{mmol})$ was added, and the mixture was stirred for $1 \mathrm{~h}$ in an ice bath and $2 \mathrm{~h}$ at room temperature. The solid was filtered, washed with dry THF, and dried at $60^{\circ} \mathrm{C}$ for $1 \mathrm{~h}$ to give $1.87 \mathrm{~g}$ of cyanuric chloride grafted on silica-gel (CCsilica). 

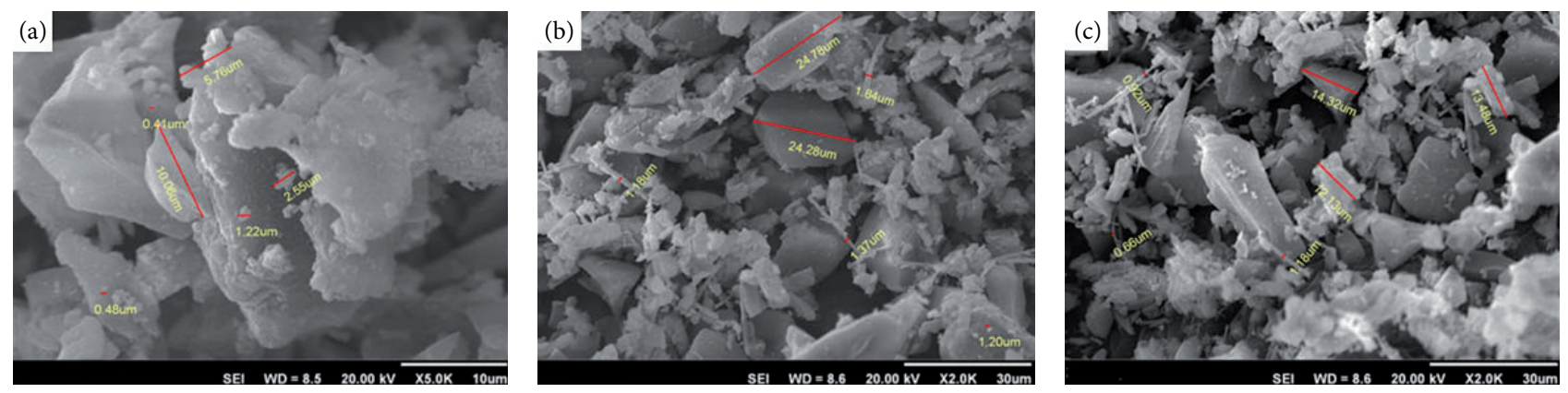

Figure 3: SEM images of (a) AT-silica and (b, c) Cu/AT-silica.

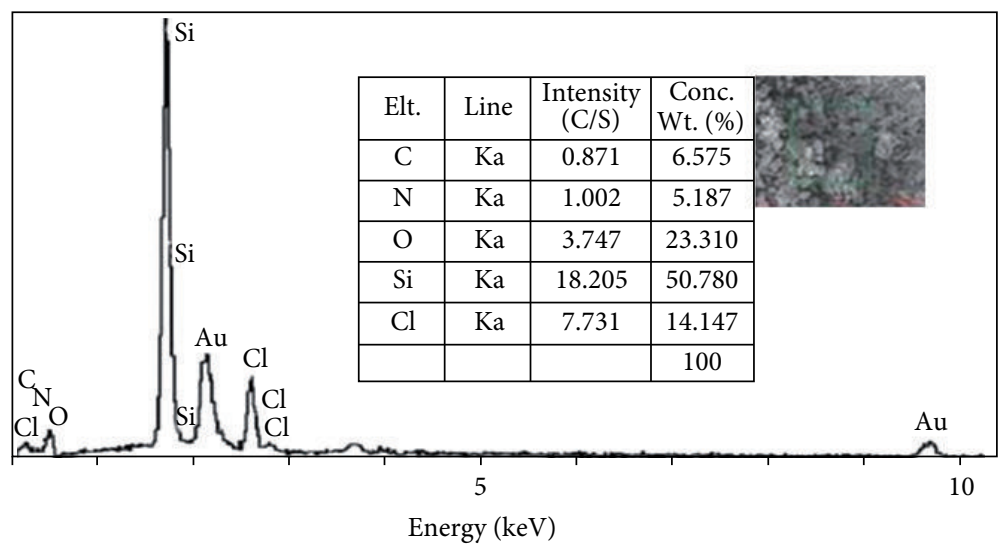

(a)

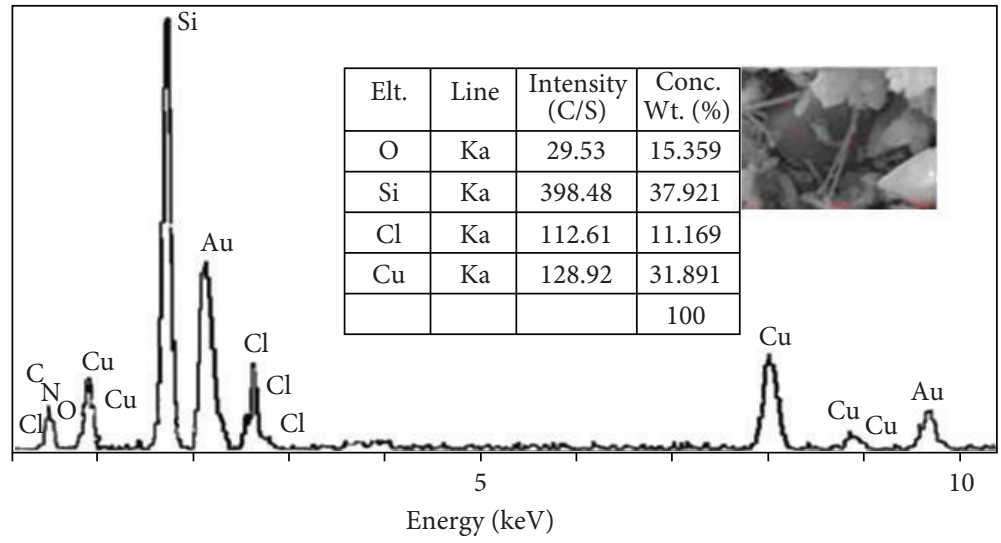

(b)

FIgURE 4: EDX images of (a) AT-silica and (b) Cu/AT-silica.

2.3. Reaction of CC-Silica with Ethylenediamine. In the second step $1.5 \mathrm{~g}$ of CC-silica in $10 \mathrm{~mL}$ dry THF was reacted with $1.5 \mathrm{~mL}$ EDA in the round bottom flask. The reaction mixture was stirred in an ice bath for $1 \mathrm{~h}$ and warmed to room temperature; TEA $(1 \mathrm{~mL})$ was added and stirred for overnight. Then, it was refluxed for $45 \mathrm{~min}$, and the solid was filtered to give $1.9 \mathrm{~g}$ animated-triazine supported on silica-gel (AT-silica).

Basic content of AT-silica was estimated by back titration using $\mathrm{NaOH}$. In a typical procedure, $5 \mathrm{~mL}$ of $\mathrm{HCl}(0.12 \mathrm{~N})$ was added to $0.2 \mathrm{~g}$ of modified silica and stirred for $30 \mathrm{~min}$. The catalyst was removed and washed successively with deionized water. The excess amount of $\mathrm{HCl}$ was titrated with $\mathrm{NaOH}$ $(0.1 \mathrm{~N})$ in the presence of phenolphthalein as an indicator. The basic content of catalyst was found to be $2.75 \mathrm{mmol} \mathrm{g}^{-1}$.

2.4. Coordination of $\mathrm{Cu}(\mathrm{II})$ onto AT-Silica. $1.4 \mathrm{~g}(7.0 \mathrm{mmol})$ of $\mathrm{Cu}(\mathrm{OAc})_{2}$ in $3 \mathrm{~mL}$ of methanol was added to the $1.2 \mathrm{~g}$ ATsilica in a round bottom flask equipment with a condenser. The reaction mixture was refluxed for $6 \mathrm{~h}$. The solid was filtered and extracted with methanol in soxhlet for $10 \mathrm{~h}$, then 


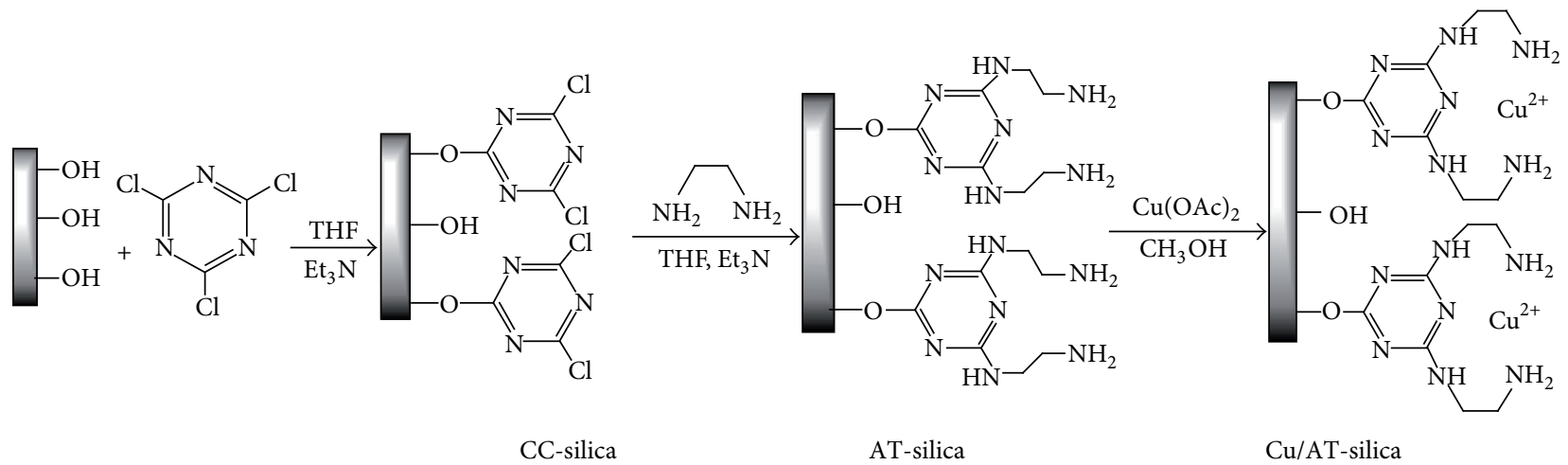

Scheme 1: Preparation of Cu/AT-silica.

TABLE 2: The effect of catalyst amount on oxidation of benzyl alcohol $^{\mathrm{a}}$.

\begin{tabular}{lccc}
\hline Entry & Catalyst amount $(\mathrm{g})$ & Yield $(\%)$ & Selectivity $(\%)$ \\
\hline 1 & - & 5 & 100 \\
2 & 0.05 & 58 & 100 \\
3 & 0.10 & 72 & 100 \\
4 & 0.15 & 80 & 100 \\
5 & 0.20 & 83 & 100 \\
\hline
\end{tabular}

Reaction conditions: benzyl alcohol $=1 \mathrm{mmol}$, solvent $=n$-hexane, amount of $\mathrm{H}_{2} \mathrm{O}_{2}=3 \mathrm{mmol}$, time $=35 \mathrm{~min}$ at reflux condition.

it was dried at $60^{\circ} \mathrm{C}$ for $1 \mathrm{~h}$ to give $\mathrm{Cu}$ (II) supported on ATsilica (Cu/AT-silica). The copper content of Cu/AT-silica was determined by atomic absorption (Perkin Elmer) and found to be $2.8 \mathrm{mmol} \mathrm{Cu}^{2+} / \mathrm{g}$.

2.5. A typical Procedure for Oxidation of Alcohol. Benzyl alcohol was selected as a model substrate for oxidation reaction and for the optimization of the process. A typical experimental procedure was as follows: to the mixture of catalyst $(0.15 \mathrm{~g}), n$-hexane $(2 \mathrm{~mL})$, and benzyl alcohol ( $1 \mathrm{mmol})$, $3 \mathrm{mmol}$ hydrogen peroxide (30\% solution) was added slowly. The reaction components were stirred at reflux condition for a period of time. The reaction process was monitored by thin-layer chromatography (TLC, silica-gel $60 \mathrm{~F}_{254}$ ) and/or gas chromatography (GC, CP WAX 52, VARIAN CP 3800). After completion of reaction, the mixture was filtered and the filtered washed with ethyl acetate. Evaporation of solvent gives the corresponding aldehyde.

\section{Results and Discussion}

Silica-gel surfaces are modified with an aliphatic amine (EDA) by cyanuric chloride as a linking agent via a two-step chemical reaction. Cyanuric chloride was chemically bound with surface hydroxyl groups of silica-gel followed by reaction with EDA (Scheme 1). Cyanuric chloride contains three chlorine atoms which can be substituted by nucleophiles in a stepwise manner. This stepwise reactivity is used to initially couple the cyanuric chloride to the silica-gel at moderate temperatures via reaction with the surface hydroxyl groups. The remaining chlorine groups on the coupled triazine are subsequently substituted by EDA at higher reaction temperatures. This new triazine derivate was applied as a coordination agent for copper (II) in methanol.

3.1. Characterizations of Catalyst. The structure of this catalyst was confirmed by FT-IR spectroscopy (PerkinElmer Spectrum Version 65). The spectrum of silica-gel shows absorptions bonds, around $1103 \mathrm{~cm}^{-1}(\mathrm{Si}-\mathrm{O})$ and $3450 \mathrm{~cm}^{-1}$ $(\mathrm{SiO}-\mathrm{H})$. After reaction of silica-gel with cyanuric chloride, new peaks at $1721 \mathrm{~cm}^{-1}, 1477 \mathrm{~cm}^{-1}$, and $1590 \mathrm{~cm}^{-1}$ (C-Cl, $\mathrm{C}=\mathrm{N}$ stretching of triazine ring) as well as existing bonds at $1103 \mathrm{~cm}^{-1}$ to $1105 \mathrm{~cm}^{-1}$ were appeared.

The FT-IR spectrum of AT-silica displays a broad absorption (with two weak peaks) around 3300-3400 $\mathrm{cm}^{-1}$ (stretching $\mathrm{N}-\mathrm{H})$ and two peaks at 1495 and $1588 \mathrm{~cm}^{-1}(\mathrm{C}=\mathrm{N}$ stretching and $\mathrm{N}-\mathrm{H}$ vibration). After reaction of AT-triazine with $\mathrm{Cu}(\mathrm{II})$, the $\mathrm{C}=\mathrm{N}$ stretching absorption bond shifted to lower frequency $\left(1435 \mathrm{~cm}^{-1}\right)$, while vibrational N-H absorption shifted to higher frequency $\left(1604 \mathrm{~cm}^{-1}\right)$, which confirms the chemical interactions of aromatic electrons and nitrogen lone pair electrons with vacant copper orbitals (Figure 1).

Figure 2 presents the DR UV-vis spectra of AT-silica and $\mathrm{Cu} / \mathrm{AT}$-silica run by UV-vis Spectrophotometer, JASCO, V$670(190-2700 \mathrm{~nm})$, Japan. The absorption around $213 \mathrm{~nm}$ in AT-silica is attributed to $n-\pi^{*}$ and $\pi-\pi^{*}$ electron transfers for the aromatic ring and amine groups. In DR UV-vis spectrum of $\mathrm{Cu} / \mathrm{AT}$-silica, new absorption around $751 \mathrm{~nm}$ appears which can be assigned to $d-d$ transitions after loading of copper.

3.2. SEM Characterization. Morphology and location of metallic species on the surface of the catalyst were analyzed by scanning electron microscopy (SEM) using an AIS-2100 (SIE mode), Korea microscope equipped with an energy dispersive $X$-ray analyzer (EDX). Figure 3 shows the SEM images of (a) AT-silica and (b, c) the immobilized copper on AT-silica (Cu/AT-silica). Clear changes in the morphologies of the catalyst after introduction of metals were observed by SEM. 
TABLE 3: Oxidation of various alcohols using $\mathrm{H}_{2} \mathrm{O}_{2}$ catalyzed by AT-silica supported $\mathrm{Cu}(\mathrm{OAc})_{2}{ }^{\mathrm{a}}$.

Entry

1<smiles>OCc1ccccc1</smiles>

2<smiles>OCc1ccccc1Cl</smiles>

$3^{\mathrm{b}}$<smiles>OCc1cccc(O)c1</smiles>

4<smiles>OCc1ccccc1O</smiles>

5

6<smiles>OCc1ccc(O)cc1</smiles>

7<smiles>Nc1ccccc1CO</smiles><smiles>COc1cccc(CO)c1</smiles>

8<smiles>O=[N+]([O-])c1ccccc1CO</smiles><smiles>O=[N+]([O-])c1ccc(CO)cc1</smiles><smiles>O=[N+]([O-])c1cccc(CO)c1</smiles><smiles>O=Cc1ccccc1</smiles><smiles>O=Cc1ccccc1Cl</smiles><smiles>O=Cc1cccc(O)c1</smiles><smiles>O=Cc1ccccc1O</smiles><smiles>O=Cc1ccc(O)cc1</smiles><smiles>Nc1ccccc1C=O</smiles><smiles>COc1cccc(C=O)c1</smiles><smiles>O=Cc1ccccc1[N+](=O)[O-]</smiles><smiles>O=Cc1ccc([N+](=O)[O-])cc1</smiles><smiles>O=Cc1cccc([N+](=O)[O-])c1</smiles> 
TABLE 3: Continued.

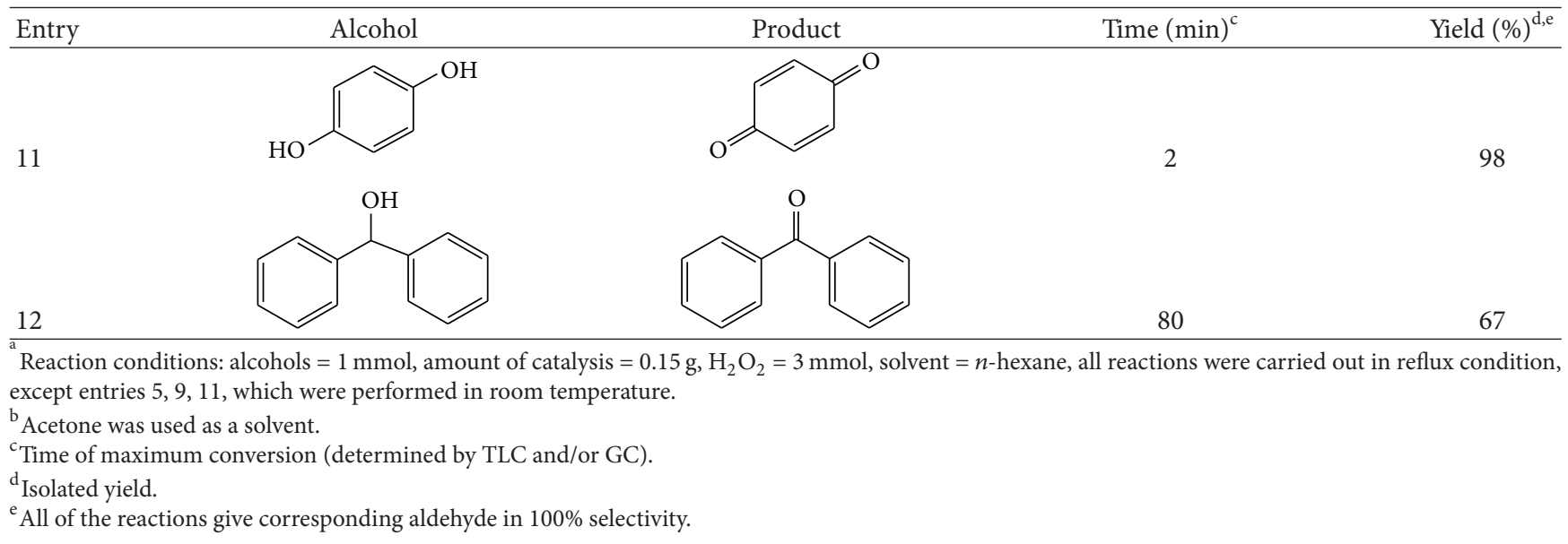

TABLE 4: Catalyst reusability of Cu/AT-silica ${ }^{a}$.

\begin{tabular}{lccc}
\hline Entry & Time $(\min )$ & Yield (\%) & Selectivity (\%) \\
\hline 1 & 35 & 80 & 100 \\
2 & 35 & 80 & 100 \\
3 & 35 & 72 & 100 \\
4 & 35 & 65 & 100 \\
\hline
\end{tabular}

Reaction conditions: alcohols $=1 \mathrm{mmol}$, amount of catalysis $=0.15 \mathrm{~g}$, $\mathrm{H}_{2} \mathrm{O}_{2}=3 \mathrm{mmol}$, solvent $=n$-hexane, all reactions were carried out in reflux condition.

Comparisons of EDX analysis of AT-silica with Cu/ATsilica (after extracting with methanol in soxhlet) confirm addition of copper to the catalyst, which suggested the formation of metal complexes with the anchored ligand (Figure 4).

3.3. Investigation of Catalytic Activity for Oxidation of Alcohols. In order to investigate the effect of solvent for oxidation reaction, different solvents such as acetonitrile, toluene, acetone, $n$-hexane, and solvent-free condition were chosen for oxidation of benzyl alcohol (Table 1). The result shows the best solvents for this reaction were $n$-hexane and toluene. In solvent-free condition, the yield of product is low.

The effect of catalyst amount on oxidation of benzyl alcohol was investigated (Table 2). The results show that with increasing of the amount of catalyst to $0.15 \mathrm{~g}$, the yield of reaction increased in fixed time. But further increasing in amount of the catalyst to $0.20 \mathrm{~g}$ did not show any considerable effect on the reactivity.

After the investigation of the effects of different parameters for the oxidation of benzyl alcohol, as a standard substrate, the best conditions were chosen and various alcohols were oxidized in the presence of a catalytic amount of $\mathrm{Cu} / \mathrm{AT}$-silica and $\mathrm{H}_{2} \mathrm{O}_{2}$ as an oxidant in refluxing $n$ hexane. Table 3 summarizes the result of various benzylic alcohols oxidation using $\mathrm{Cu} / \mathrm{AT}$-silica. The reaction yields were slightly dependent on substituents $\left(-\mathrm{Cl},-\mathrm{OH},-\mathrm{OCH}_{3}\right.$, $-\mathrm{NO}_{2}$, and $-\mathrm{NH}_{2}$ ) and on their positions.
Primary benzylic alcohols with electron donating substituent such as $o$ - and $p$-hydroxy, and $o$-amino were converted to the corresponding aldehydes in excellent yield (entry 3-6). On the other hand, the highest decelerating effect was observed with strong electron accepting nitrosubstituents (entry 8-10), whereas halogen substituents cause medium yields (entry 2). Similarly, the oxidation of secondary benzylic alcohol was also giving the corresponding ketone (entry 12). The overoxidation of aldehydes into carboxylic acids was not observed, and all of the corresponding aldehydes were obtained in excellent selectivity.

3.4. Catalyst Recycling. One of the main reasons for supporting a homogeneous metal complex on the silica-gel is to enhance the life of the resulting catalyst. To investigate the reusability of silica-gel-based complex catalysts, the catalyst was separated by filtration after the first run, dried under vacuum, and then subjected to a second run with further addition of substrates in appropriate amounts under optimum reaction conditions, and the yield and structure of the final products were compared with those of the original run. As shown in Table 4, the catalyst could be used for oxidation of alcohols up to four times without loss of its selectivity.

\section{Conclusions}

In this study, a novel heterogeneous catalyst (Cu/ATsilica) containing amino-functionalized triazine supported on silica-gel synthesized via reaction of cyanuric chloride with silica-gel is followed by reaction with ethylenediamine and coordination of copper (II). FT-IR spectroscopy and $X$ ray diffraction show the structure of Cu/AT-silica and confirm that the ligand is attached to the silica surface. DRUVVis, atomic absorption, and EDX analysis also approve the existence of copper on the resulting catalyst. This new triazine derivate was applied as a highly efficient catalyst for the selective and environmentally friendly oxidation of benzylic alcohols to corresponding aldehydes and ketones with hydrogen peroxide. The main advantages of this catalytic system are easy catalyst preparation, mild reaction conditions, and easy 
workup procedure, low cost of the catalyst, and finally it can be recycled and reused several times without loss of activity.

\section{Acknowledgment}

The authors wish to express our gratitude to Dr. R. Fazaeli for her helpful discussions.

\section{References}

[1] G. Blotny, "Recent applications of 2,4,6-trichloro-1,3,5-triazine and its derivatives in organic synthesis," Tetrahedron, vol. 62, no. 41, pp. 9507-9522, 2006.

[2] F. Hamon, G. Prié, F. Lecornué, and S. Papot, "Cyanuric chloride: an efficient reagent for the Lossen rearrangement," Tetrahedron Letters, vol. 50, no. 49, pp. 6800-6802, 2009.

[3] A. R. Silva, C. Freire, B. de Castro, M. M. A. Freitas, and J. L. Figueiredo, "Anchoring of a nickel(II) Schiff base complex onto activated carbon mediated by cyanuric chloride," Microporous and Mesoporous Materials, vol. 46, no. 2-3, pp. 211-221, 2001.

[4] A. R. Silva, V. Budarin, J. H. Clark, C. Freire, and B. de Castro, "Organo-functionalized activated carbons as supports for the covalent attachment of a chiral manganese(III) salen complex," Carbon, vol. 45, no. 10, pp. 1951-1964, 2007.

[5] I. Kuźniarska-Biernacka, A. R. Silva, A. P. Carvalho, J. Pires, and C. Freire, "Direct immobilisation versus covalent attachment of a $\mathrm{Mn}(\mathrm{III})$ salen complex onto an Al-pillared clay and influence in the catalytic epoxidation of styrene," Journal of Molecular Catalysis A, vol. 278, no. 1-2, pp. 82-91, 2007.

[6] N. Strashnikova, V. Papper, P. Parkhomyuk, G. I. Likhtenshtein, V. Ratner, and R. Marks, "Local medium effects in the photochemical behavior of substituted stilbenes immobilized on quartz surfaces," Journal of Photochemistry and Photobiology A, vol. 122, no. 2, pp. 133-142, 1999.

[7] D. Schaubroeck, J. De Baets, T. Desmet, S. Van Vlierberghe, E. Schacht, and A. Van Calster, "Introduction of amino groups on the surface of thin photo definable epoxy resin layers via chemical modification," Applied Surface Science, vol. 255, no. 21, pp. 8780-8787, 2009.

[8] D. Schaubroeck, J. De Baets, T. Desmet et al., "Surface modification of an epoxy resin with polyamines via cyanuric chloride coupling," Applied Surface Science, vol. 256, no. 21, pp. 6269-6278, 2010.

[9] A. R. Silva, K. Wilson, J. H. Clark, and C. Freire, "Covalent attachment of chiral manganese(III) salen complexes onto functionalised hexagonal mesoporous silica and application to the asymmetric epoxidation of alkenes," Microporous and Mesoporous Materials, vol. 91, no. 1-3, pp. 128-138, 2006.

[10] S. E. Martin and A. Garrone, "Efficient solvent-free iron (III) catalyzed oxidation of alcohols by hydrogen peroxide," Tetrahedron Letters, vol. 44, no. 3, pp. 549-552, 2003.

[11] Y. Shvo and V. Goldman-Lev, "Catalytic oxidation of alcohols with allyl diethyl phosphate and palladium acetate," Journal of Organometallic Chemistry, vol. 650, no. 1-2, pp. 151-156, 2002.

[12] L. Lin, M. Juanjuan, J. Liuyan, and W. Yunyang, "Molecular sieve promoted copper catalyzed aerobic oxidation of alcohols to corresponding aldehydes or ketones," Journal of Molecular Catalysis A, vol. 291, no. 1-2, pp. 1-4, 2008.
[13] S. Mannam and G. Sekar, "CuCl catalyzed selective oxidation of primary alcohols to carboxylic acids with tert-butyl hydroperoxide at room temperature," Tetrahedron Letters, vol. 49, no. 15, pp. 2457-2460, 2008.

[14] X. Fan, Y. Qu, Y. Wang, X. Zhang, and J. Wang, "Ru(III)catalyzed oxidation of homopropargyl alcohols in ionic liquid: an efficient and green route to 1,2-allenic ketones," Tetrahedron Letters, vol. 51, no. 16, pp. 2123-2126, 2010.

[15] M. Hunsen, "Pyridinium chlorochromate catalyzed oxidation of alcohols to aldehydes and ketones with periodic acid," Tetrahedron Letters, vol. 46, no. 10, pp. 1651-1653, 2005.

[16] S. Velusamy, A. Srinivasan, and T. Punniyamurthy, "Copper(II) catalyzed selective oxidation of primary alcohols to aldehydes with atmospheric oxygen," Tetrahedron Letters, vol. 47, no. 6, pp. 923-926, 2006.

[17] A. Ezabadi, G. R. Najafi, and M. M. Hashemi, "A green and efficient oxidation of benzylic alcohols using $\mathrm{H}_{2} \mathrm{O}_{2}$ catalyzed by montmorillonite $\mathrm{K}-10$ supported $\mathrm{CoCl}_{2}$," Chinese Chemical Letters, vol. 19, no. 11, pp. 1277-1280, 2008.

[18] X. Wang, G. Wu, J. Li, N. Zhao, W. Wei, and Y. Sun, "Selective oxidation of benzyl alcohol catalyzed by $\mathrm{Cr}$ (salen) complexes immobilized on MCM-41," Journal of Molecular Catalysis A, vol. 276, no. 1-2, pp. 86-94, 2007.

[19] M. Alizadeh, F. Farzaneh, and M. Ghandi, "Heterogeneous catalysis in the liquid phase oxidation of alcohols by $\mathrm{Cu}$ (II) complexes immobilized between silicate layers of bentonite," Journal of Molecular Catalysis A, vol. 194, no. 1-2, pp. 283-287, 2003.

[20] B. P. Buffin, J. P. Clarkson, N. L. Belitz, and A. Kundu, "Pd(II)biquinoline catalyzed aerobic oxidation of alcohols in water," Journal of Molecular Catalysis A, vol. 225, no. 1, pp. 111-116, 2005.

[21] S. L. Jain, V. B. Sharma, and B. Sain, "Highly efficient and selective oxidation of secondary alcohols to ketones under organic solvent and transition metal free conditions," Tetrahedron, vol. 62, no. 29, pp. 6841-6847, 2006. 

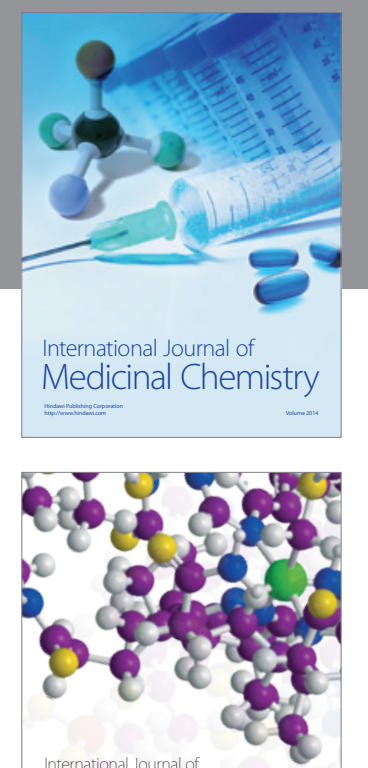

\section{Carbohydrate} Chemistry

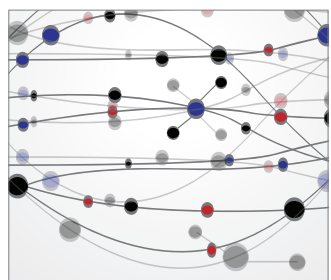

The Scientific World Journal
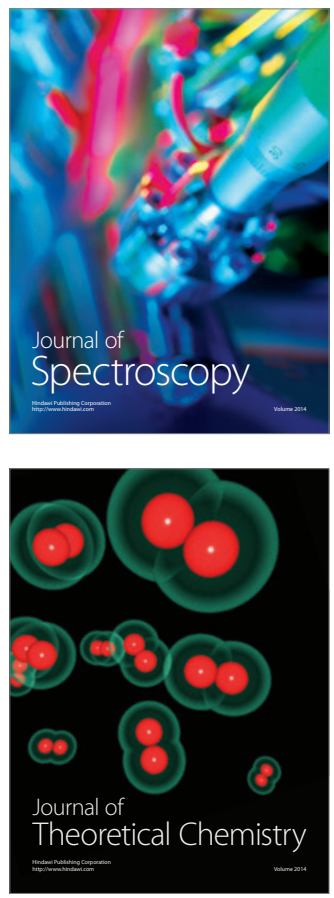
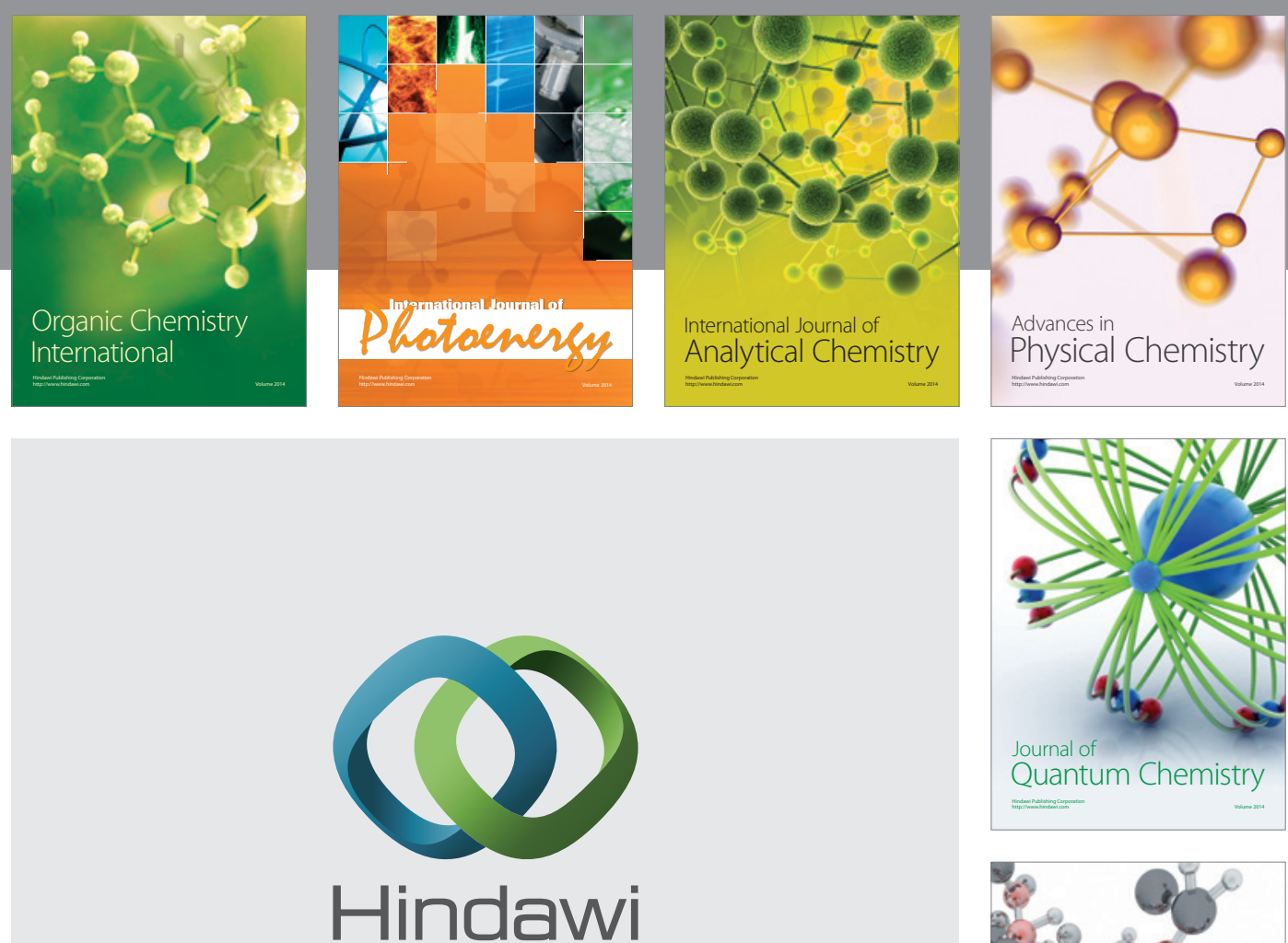

Submit your manuscripts at

http://www.hindawi.com

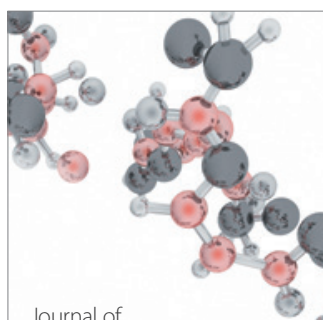

Analytical Methods

in Chemistry

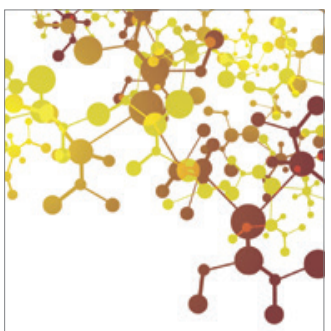

Journal of

Applied Chemistry

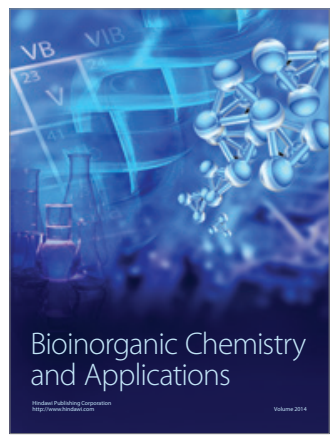

Inorganic Chemistry
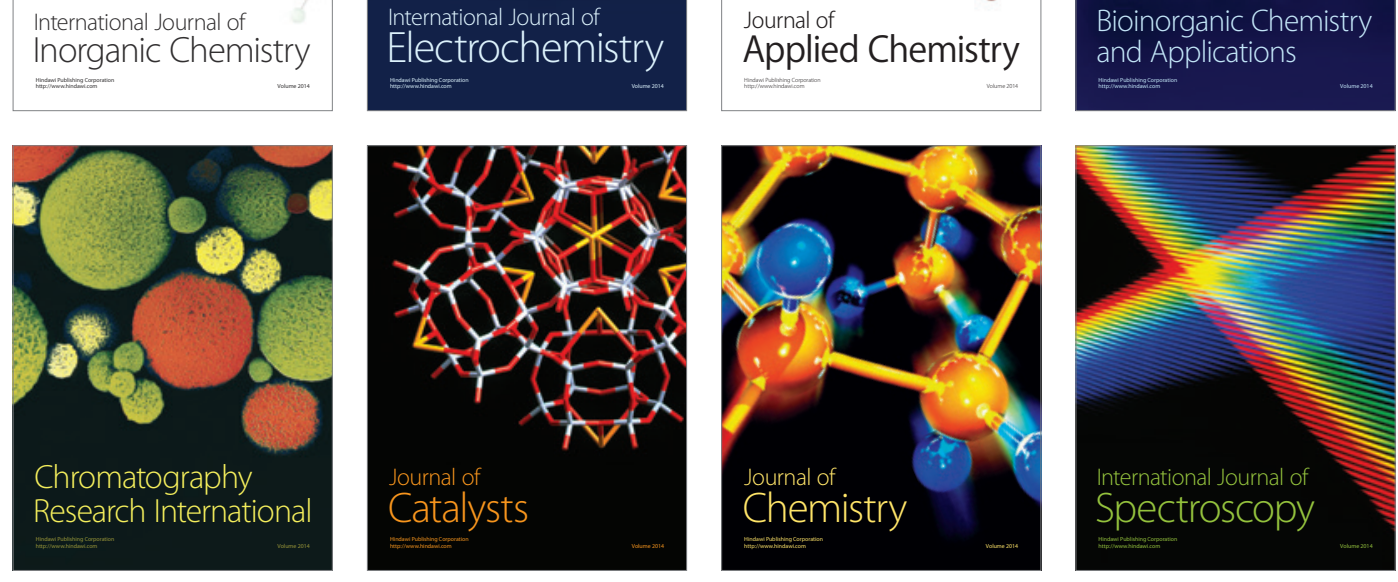